\title{
How to Teach Concern: Inspiring Speech-Language Pathology Graduate Students to Develop Empathy and Advocacy with the Power of Personal Stories
}

Lesley Sylvan

Montclair State University, sylvanl@montclair.edu

DOI: https://doi.org/10.30707/TLCSD3.2Sylvan

Follow this and additional works at: https://ir.library.illinoisstate.edu/tlcsd

Part of the Scholarship of Teaching and Learning Commons

\section{Recommended Citation}

Sylvan, Lesley (2019) "How to Teach Concern: Inspiring Speech-Language Pathology Graduate Students to Develop Empathy and Advocacy with the Power of Personal Stories," Teaching and Learning in Communication Sciences \& Disorders: Vol. 3: Iss. 2, Article 9.

DOI: https://doi.org/10.30707/TLCSD3.2Sylvan

Available at: https://ir.library.illinoisstate.edu/tlcsd/vol3/iss2/9

This Scholarship of Teaching and Learning Research is brought to you for free and open access by ISU ReD: Research and eData. It has been accepted for inclusion in Teaching and Learning in Communication Sciences \& Disorders by an authorized editor of ISU ReD: Research and eData. For more information, please contact ISUReD@ilstu.edu. 


\title{
How to Teach Concern: Inspiring Speech-Language Pathology Graduate Students to Develop Empathy and Advocacy with the Power of Personal Stories
}

\author{
Abstract \\ "Concern for individuals served" is one of the new Professional Practice Competencies in the updated \\ 2017 standards for accreditation of graduate education according to the Council on Academic \\ Accreditation in Audiology and Speech-Language Pathology. In light of this recent standard, graduate \\ programs must facilitate skill development related to this competency. How does one teach "concern" \\ and "compassion" in an authentic manner? This study investigates the impact of an assignment designed \\ to address this standard. The assignment under investigation involves an in-class "book club" centered \\ around reading non-fiction books detailing personal accounts of families impacted by disabilities. In order \\ to understand the impact of the assignment, reflective essays were collected and an anonymous survey \\ of students' perceptions was administered. The findings show that this assignment was perceived \\ favorably by students and that the assignment provided them with an authentic look at the lives of \\ families with children impacted by disabilities, which in turn, led to greater feelings of empathy and \\ understanding. Additionally, students were inspired to become strong advocates for children with \\ disabilities. These findings suggest that it is possible as well as practical for faculty to address this \\ professional standard in a meaningful way within the graduate-level classroom.
}

\section{Keywords}

professional practice competencies, concern for individuals served, teach concern, graduate program, book club, empathy, compassion, understanding, advocacy 
"Concern for individuals served" is one of the new Professional Practice Competencies (3.1.1B) that speech-language pathology (SLP) graduate students must demonstrate according to the new Council on Academic Accreditation in Audiology and Speech-Language Pathology (CAA) standards for accreditation of graduate education programs in audiology and speech-language pathology, as of 2017 (CAA, 2018, pp. 20-21). In order to demonstrate skills in this area, students must "show evidence of care, compassion, and appropriate empathy during interactions with each individual served, family members, caregivers, and any others involved in care" (CAA, 2018, p. 21) as well as "encourage active involvement of the individual served in his or her own care" (CAA, 2018, p. 21). This language is new for the 2017 standards. The previous version of the CAA Professional Practice Competencies, published in 2008 and revised in 2010, did not mention empathy specifically but rather stated that graduate programs should train students to demonstrate, "effective interaction with patients, families, professionals, and other individuals, as appropriate" (CAA, 2010, p. 61).

This new professional practice standard seems particularly applicable to working with the pediatric population and interacting appropriately with their families, especially those whose children are diagnosed with disabilities. The ability to compassionately interact and empower parents to advocate for their children is increasingly recognized as critically important for all educators (Park, Stone, \& Holloway, 2017). The benefit of a parent's direct engagement (i.e., assisting child with homework) and indirect engagement (i.e., communication with child's teachers) with their child's success in academic settings is well-documented (American Federation of Teachers, 2010; Kreider, Mayer, \& Vaughan, 1999). According to the American Federation of Teachers (2010), parent involvement raises students' academic achievement and positively affects their child's motivation for learning, behavior, attendance as well as their general attitude about homework and school. Additionally, studies have shown that parent training in the area of communication is not only associated with positive outcomes for children but also feelings of confidence for parents (Dunst \& Dempsey, 2007; Roberts, Hensle, \& Brooks, 2016).

While it is clear that the ability to demonstrate "concern for the individual served" is an important area for speech-language pathologists (SLPs), it is less than straight forward to determine the best ways for academic programs to offer graduate students in speech-language pathology master's degree programs with appropriate content and opportunities to develop skills in this area. One might rightly wonder if this is a teachable skill or if "concern" is just a human instinct. In his 2009 book, "Born to be Good: The Science of a Meaningful Life," Dacher Keltner argues that concern for others is a fundamentally human trait and that humans are successful as a species because of our nurturing, altruistic and compassionate traits. Given this, it would seem that the ability to show concern and compassion for other people, especially those put in our care, might be a fundamental human capacity.

However, factors such as stress, high demands for productivity, and the litigious atmosphere in which care is provided present real barriers for professionals seeking to demonstrate concern and compassion in caretaking and educational roles (Felton, 1998; Sylvan, 2014). To start with, families whose children are impacted by disabilities face both financial and personal stress (Woodman, 2014). Further, many SLPs manage large caseloads and have high demands for productivity (Cutter \& Polovoy, 2014; Sylvan, 2014). The fact that the median caseload for schoolbased SLPs is 48 students according to the 2018 American Speech-Language-Hearing Association 
(ASHA) school survey underscores this fact (ASHA, 2018). Further, interactions between clinicians and parents are often situated in contexts where due process hearings, lawsuits, and confrontation between parents and professionals seem to be par for the course (Hehir, 1990; Hehir, et al., 2005; Sylvan, 2018). Within this context, research shows many parents may present as argumentative which may cause an SLP's first reaction to be one of defensiveness rather than understanding (Sylvan, 2014). In this context, building a compassionate and positive relationship between clinicians and families is a difficult task. On the other hand, these litigious and challenging relationships accentuate the urgent need for more kind and empathetic care from SLPs for children with disabilities and their families.

Previous research has consistently demonstrated that SLPs find counseling parents of children with disabilities to be a challenging area of professional practice. While SLPs are often in the position of needing to break "bad news" to parents or counsel them about how to best take care of and advocate for their children (De Froy, 2018; Gold \& Gold, 2018), SLPs report having increased feelings of anxiety before doing so (Gold \& Gold, 2018). Studies show that without any explicit attention or training paid to the subject, many SLP graduate students feel ill-equipped by their master's programs to effectively counsel and appropriately communicate with parents whose children have disabilities suggesting this is an area where greater training is needed (Luterman, 2001; Noss \& Yeager, 2016). Additionally, program faculty in speech-language pathology master's degree programs have reported the difficulty of conveying professional skills in counseling to graduate students (Noss \& Yeager, 2016).

\section{Current Study}

How can graduate programs address the responsibility to provide graduate students with context and opportunities to address the "concern for individuals served" standard? Certainly, clinical experiences in which graduate students interact directly with clients may provide natural opportunities for graduate students to gain related skills. However, it is both sensible and important to design activities to meet this important standard within the context of the didactic/ coursework component of the master's degree programs in speech-language pathology. The purpose of this study is to investigate the impact of an assignment meant to address this standard within this context. The assignment under investigation involved student participation in an in-class "book club" centered around reading non-fiction books detailing personal accounts of children and families impacted by disabilities.

This research study addresses an important gap in the literature regarding teaching qualities such as empathy and compassion to graduate students in speech-language pathology. While no previous research on this exact topic has been identified, this study builds on previous research showing that teaching methodology in the classroom context does influence student perception and conceptualizations of disability more generally. Yu \& Epstein (2011) demonstrated that shifts in teaching methods related to the medical, social, and experiential continuum of disability models impacted how students studying to become SLPs conceptualized the nature of developmental communication disorders. Yu and Epstein (2011) demonstrated changes in student thinking through analysis of student written work in the form of reflection papers. The current study also relies on analysis of student reflection papers as a primary source of data. Specifically, this study looks at student reflection papers as well as student survey results in order to understand the impact 
of an assignment involving reading non-fiction books featuring personal accounts of families experiencing disabilities.

This assignment under investigation (i.e., the "book club" project) was presented to students with the goal of addressing the "concern for individuals served" professional competency standard. A primary purpose of the assignment was to deepen students' understanding of how families experience disabilities with the goal of helping prepare students to be sensitive and empathic clinicians who are responsive to the experiences of families raising a child with a disability. This paper investigates the impact of this assignment on student learning through analysis of student reflection papers, as well as how the assignment was perceived by students through analysis of an associated survey.

\section{Methods}

Participants. Participants in this study consisted of 34 graduate students enrolled in three sections of CSND 587: Language Disorders in School Age Children in the Communication Sciences and Disorders master's program at Montclair State University. Eight of the students completed the course in the fall semester of 2017 and the remaining students completed the course during the spring semester of 2018. In the spring semester, students were divided into two course sections.

CSND 587 is a required graduate-level course taken in the final semester of graduate coursework before students begin the off-campus practicum component of their graduate program. All of the students enrolled in this class have completed at least two semesters as graduate clinicians in the university speech and language clinic. In their roles as graduate clinicians, all students have worked with at least one pediatric client as part of their clinical training. As part of their graduate training, students in this class have completed coursework that includes clinical processes, diagnostic procedures, and language disorders in toddlers and preschool-aged children. All students participating in this study demonstrated regular attendance to CSND 587 and participated actively in all assignments throughout the semester. Specific demographic information (e.g., age, ethnicity) of students was not collected for this study.

The Assignment - The "Book Club" Project. For the "book club" project assignment in CSND 587 (Language Disorders in School Age Children), students were given the choice of three books (see Table 1) to select from and were instructed to read their chosen book over the first 10 weeks of the 14-week-long semester. The chosen books were selected by the instructor because they were judged to be well-written, informative non-fiction books with contained information about how families and children deal with varying types of disabilities which impact speech and language functioning. These chosen books were required reading for this course in addition to a traditional textbook and selected peer-reviewed research articles. Participation in the "book club" project accounted for $15 \%$ of the grade in this course. The assignment had three key components:

Book clubs. At four designated times spread evenly over the semester, students met in "book clubs" with other classmates who had selected to read the same book for this assignment. During "book club" meetings students were directed to share their reactions to the book and discuss how the book related to course content and their own clinical experiences. The rationale for including these in-class "book club" meetings was based on the idea that a collective literary experience gives one 
the opportunity to further reflect upon ideas they may have not considered just from reading independently (Story, 2017). The fact that these discussions were relatively unstructured was meant to mimic the experience of participating in a book club in the community context (Ahlin, 2016; Lloyd, 2011).

Table 1: Choice of Three Books Given to Students

\begin{tabular}{|c|c|c|}
\hline Book & Author(s) & Brief Synopsis \\
\hline $\begin{array}{l}\text { Schuyler's Monster: A Father's } \\
\text { Journey with His Wordless } \\
\text { Daughter }\end{array}$ & $\begin{array}{l}\text { Robert Rummel- } \\
\text { Hudson }\end{array}$ & $\begin{array}{l}\text { A father's perspective on the journey } \\
\text { he entails in navigating society for his } \\
\text { daughter, Schuyler, who is eventually } \\
\text { diagnosed with an extremely rare } \\
\text { neurological disorder }\end{array}$ \\
\hline $\begin{array}{l}\text { An Uncomplicated Life: A } \\
\text { Father's Memoir of His } \\
\text { Exceptional Daughter }\end{array}$ & Paul Daugherty & $\begin{array}{l}\text { A father's loving, anecdotal account of } \\
\text { his experiences raising his daughter, } \\
\text { Jillian, who has Down syndrome }\end{array}$ \\
\hline $\begin{array}{l}\text { How Did You Get Here? } \\
\text { Students with Disabilities and } \\
\text { Their Journeys to Harvard }\end{array}$ & $\begin{array}{l}\text { Thomas Hehir, } \\
\text { Laura A. } \\
\text { Schifter, Wendy } \\
\text { S. Harbour, \& } \\
\text { David H. Rose }\end{array}$ & $\begin{array}{l}\text { A chronical of the educational } \\
\text { experiences of sixteen students with } \\
\text { disabilities and their journey to } \\
\text { achieving personal and academic } \\
\text { success at Harvard University }\end{array}$ \\
\hline
\end{tabular}

Reflection paper. At the end of the semester, students were required to write a two-page reflection paper explaining how the "book club" project enhanced their learning of the class material. The following prompts were provided to students to guide their reflection papers: (a) How did this book enhance your perspective on how children and families experience disabilities? (b) How did reading this book contribute to your growing knowledge of pediatric speech-language disabilities? and (c) Would you recommend this book to others?

Presentation. At the last designated "book club", students were given time to plan an informal class presentation to share their experiences reading their book with the rest of the class.

Data Sources. The analysis in this paper focuses on two sources of information: student reflection papers and the results of an anonymous survey on students' perceptions of the assignment. The student reflection papers were required elements of the class. The papers were analyzed after the course was completed. At the end of the course, the students were invited, but not required to participate, in an anonymous online survey regarding their impressions of this assignment. This project was approved by the Institutional Review Board at the researcher's university. 


\section{Analysis.}

Reflection papers. After grading for the semester concluded, all reflection papers $(n=34)$ were deidentified and uploaded as documents into coding and sorting qualitative research software (Dedoose). The research team, consisting of two graduate-level research assistants and the author, collaborated to define codes and identify transcripts with codes.

Codes were developed through a combination of open coding and codes derived from the study's literature-based conceptual framework (Maxwell, 2005; Strauss \& Corbin, 1998). Early in the analysis process, the research team met and proposed an initial set of codes based on the study's literature-based conceptual framework and assignment rationale. This initial set of codes included key concepts such as "empathy," "sympathy," "compassion," "up-close/ personal," "reality over theory", and "applicable to clinical experiences." Using this list of codes as a starting point, each reflection paper was reviewed by each member of the research team and a meeting was held to discuss emerging themes that were identified through open coding. Each team member presented a list of ten to twelve codes that they felt best captured the data. While several codes were found independently by each member of the team (i.e., "importance of individual over diagnostic label"), a discussion was held about modifying certain codes on the original list, adding additional codes, or consolidating codes. For example, through this discussion, the codes "empathy," "sympathy" and "compassion" were consolidated. The codes "importance of SLP's words on people's lives" and "impact of SLP on personal \& family life" were proposed and defined as part of a team discussion.

In a manner consistent with qualitative research methodology (Bogdan \& Biklen, 1998), coding and analysis was an iterative and collaborative process which involved frequent meetings with the research team. In order to come to a consensus, each reflection paper was individually reviewed and discussed until the research team reached consensus on the appropriate codes for applicable transcript segments. As appropriate, earlier transcripts were corrected for later code modifications or alterations. Given the iterative and flexible nature of the code discussions and modifications, an inter-rater reliability rate was not determined.

Following coding, the data were reorganized from an event basis into a topic basis. The research team created a file containing all transcript segments related to an individual code so that codes be considered and analyzed as a group. Using this coding scheme as a starting point, the research team developed analytic memos discussing how individual codes mapped on the major themes and ideas related to the research goals (Seidman, 2006). Based on ideas explored in these analytic memos, the codes were organized into two sets. One set focused on the students' personal or emotions reactions to the book (i.e., empathy, inspirational) and the other set of codes focused on content or learned information from the books (i.e., applicable to clinical experiences, knowledge on school-based processes). See Table 2 for a list and description of each code as well as the percentage of transcripts tagged by each listed code. See Table 3 for example quotes from transcript segments marked with each code. 
Teaching and Learning in Communication Sciences \& Disorders, Vol. 3 [2019], Iss. 2, Art. 9

Table 2: Major Categories and Associated Codes Identified Within Reflection Papers

Code/ Code Description

Percentage

Reflection

Papers

Student's Personal or Emotional Reactions to the Book

Up-close/personal: Used to identify the student gaining an intimate perspective

$82 \%$

Inspirational: Used to identify students being inspired in any aspect by their book $79 \%$

Surprising: Used to identify the student not expecting or anticipating something $65 \%$ that occurred in the book

Empathy: Used to identify when students understood and shared the book 59\% characters' experiences and emotions

Reality of disabilities over theory: Used to identify when students were getting a $53 \%$ realistic perspective through seeing a difference between theory and reality

Impact of SLP on personal \& family life: Used to identify how the SLP had truly $26 \%$ impacted the book characters in their personal and family life

\section{Content or Learned Information from Books}

Applicable to clinical experiences: Used to identify when students related the $79 \%$ content of the book to their previous, current, or future clinical experiences

Importance of individual over diagnostic label: Used to identify when students $47 \%$ looked at the character's individuality rather than their diagnosis

Knowledge of school-based processes: Used to identify when students gained 29\% knowledge about the different processes that occur in school settings

Reinforce class material: Used to identify when students described the content of $24 \%$ the book being supplementing what they had learned in class

Importance of SLP's words on people's lives: Used to identify when students had $18 \%$ a realization about the importance of words as they can leave a significant, longlasting effect for the listener 
Table 3: Codes Identified Within Reflection Papers and Example Quotes

\begin{tabular}{|c|c|}
\hline Code & Quote \\
\hline \multicolumn{2}{|c|}{ Student's Personal or Emotional Reactions to the Book } \\
\hline $\begin{array}{l}\text { Up- } \\
\text { close/personal }\end{array}$ & $\begin{array}{l}\text { "I was able to see life through a parent's perspective, providing me with a } \\
\text { glimpse of the everyday emotional ups and downs that accompany raising a } \\
\text { child with special needs." }\end{array}$ \\
\hline Inspirational & $\begin{array}{l}\text { "In reading this book, I was inspired by the tenacity of the interviewees and } \\
\text { authors alike. Each and every student with a disability relentlessly navigated a } \\
\text { path built for typically developing peers, on a quest to pursue lofty goals." }\end{array}$ \\
\hline Surprising & $\begin{array}{l}\text { "One aspect of this book that surprised me was how long it took to find } \\
\text { Schuyler's diagnosis. So many different professionals worked to try to find her } \\
\text { diagnosis, and it took a lot of time and money to finally discover it." }\end{array}$ \\
\hline Empathy & $\begin{array}{l}\text { "This book creates a deeper understanding of the struggle families go through } \\
\text { when they have a child with a disability such as DS." }\end{array}$ \\
\hline $\begin{array}{l}\text { Reality of } \\
\text { disabilities over } \\
\text { theory }\end{array}$ & $\begin{array}{l}\text { "I was able to see life through a parent's perspective, providing me with a } \\
\text { glimpse of the everyday emotional ups and downs that accompany raising a } \\
\text { child with special needs." }\end{array}$ \\
\hline $\begin{array}{l}\text { Impact of SLP } \\
\text { on personal \& } \\
\text { family life }\end{array}$ & $\begin{array}{l}\text { "I would recommend this book to an aspiring SLP because it demonstrates the } \\
\text { positive influence we can have on an individual. One of Jillian's first SLPs was } \\
\text { coined 'her first guardian angel' by the author." }\end{array}$ \\
\hline \multicolumn{2}{|c|}{ Content or Learned Information from Books } \\
\hline $\begin{array}{l}\text { Applicable to } \\
\text { clinical } \\
\text { experiences }\end{array}$ & $\begin{array}{l}\text { "This book helped me to realize that with pediatric speech-language } \\
\text { disabilities, there is often not going to be one right answer for what to do with } \\
\text { each child. Therefore, client-centered therapy with trial and error must be part } \\
\text { of the process for determining what is best for our clients." }\end{array}$ \\
\hline $\begin{array}{l}\text { Importance of } \\
\text { individual over } \\
\text { diagnostic label }\end{array}$ & $\begin{array}{l}\text { "This book is a reminder to professionals in special education to look at each } \\
\text { student as a whole person, and not just a set of documents and standardized test } \\
\text { scores." }\end{array}$ \\
\hline $\begin{array}{l}\text { Knowledge of } \\
\text { school-based } \\
\text { processes }\end{array}$ & $\begin{array}{l}\text { "It also made me aware of the various potential accommodations that can be } \\
\text { made for children with disabilities depending on their strengths and } \\
\text { weaknesses; for example, Jillian reportedly benefitted from a reduced course } \\
\text { load, repetition, and visual cues." }\end{array}$ \\
\hline $\begin{array}{l}\text { Reinforce class } \\
\text { material }\end{array}$ & $\begin{array}{l}\text { "Jillian's language skills and difficulties are consistent with what we have } \\
\text { learned throughout our coursework so far." }\end{array}$ \\
\hline $\begin{array}{l}\text { Importance of } \\
\text { SLP's words on } \\
\text { people's lives }\end{array}$ & $\begin{array}{l}\text { "In this way, it is important for SLPs to always consider the impact of how our } \\
\text { words affect parents. It is important to be informative, honest, and considerate } \\
\text { during these meetings." }\end{array}$ \\
\hline
\end{tabular}


Survey. After completing the required book reflection paper, the students were asked to complete a voluntary survey about the assignment. In total, 31 out of 34 students agreed to participate in the survey yielding a $91 \%$ response rate. Table 4 provides the means and standard deviations for the survey investigating students' self-report ratings of their compliance, engagement and impressions of the assignment. The survey contained 11 items each presented as a Likert-type scale ranging from strongly agree (value of 5) to strongly disagree (value of 1).

Table 4: Survey Items Based on a 5-Point Likert-Type Scale

\begin{tabular}{lc} 
Survey Item & Mean $\begin{array}{l}\text { Standard } \\
\text { Deviation }\end{array}$ \\
\hline
\end{tabular}

1. For this class, I carefully read all assigned textbook chapters and $\begin{array}{lll}1.97 & 1.15\end{array}$ empirical articles; I didn't skim them.

2. I carefully read the "book club" book completely for this class; I didn't $4.32 \quad 0.93$ skim it.

3. I felt the textbook assigned for this class was engaging; I looked $\begin{array}{lll}1.74 & 0.91\end{array}$ forward to reading assigned chapters.

4. I felt the book written for popular audiences (i.e., my "book club” $3.87 \quad \begin{array}{lll}1.10\end{array}$ book) assigned for this class was engaging; I looked forward to reading it.

5. I gained a new perspective on the subjective matter covered in this course by reading a book written for popular audiences.

6. Reading a book written for popular audiences helped me engage with $\quad \begin{array}{ll}4.10 & 0.82\end{array}$ course content on a deeper level.

7. I hope that future classes I complete as part of my degree will include 3.16 a book written for a popular audience.

8. I feel inspired to read more books written for popular audiences about $\quad \begin{array}{ll}3.90 & 0.89\end{array}$ the subject matter covered in this course after reading the assigned book written for popular audiences.

9. I wish the professor had selected the book for us to read instead of $\quad \begin{array}{ll}1.52 & 0.84\end{array}$ providing a choice of books to select from for this assignment.

10. I felt the "book club" meetings were a good use of class time. $\quad 3.13 \quad 0.91$

11. Overall, I felt the "book club" assignment added value to this class. $4.13 \quad 0.66$

Note: The survey contained items based on a 5-point Likert-type scale ranging from strongly agree (value of 5) to strongly disagree (value of 1). 


\section{Results}

The goal of the assignment under investigation (i.e., the "book club" project) was to provide content and opportunities for students to develop skills related to the "concern for individuals served" professional competency standard as described by the CAA. Detailed analysis of student reflection papers as well as a survey gauging student perception of the assignment suggests that this assignment inspired student learning related to this standard and was largely viewed by students as adding value to their experiences in a graduate class. A close look at how and why this assignment appears to be impactful provides a useful case study on how graduate programs in speech-language pathology can provide content and experiences related to the "concern for individuals served" professional practice competency within the didactic/academic component of their programs.

The "Personal" Look at Disability Led to Students' Feelings of Empathy and Understanding. Data suggest that students found that this "book club" project provided them with an authentic and compelling look at the lives of families and children impacted by disabilities and this experience led to a deeper knowledge of how children and families experience disabilities. The fact that $82 \%$ of reflection papers were coded as "up-close/personal," a code used to identify the student gaining an intimate perspective, underscores the fact that it was the "personal" perspective on disabilities that made a major impression on students in terms of their learning. In the words of one student, "I knew about the many internal stresses families can face, such as financial hardship, divorce, denial, depression, mourning, and even social isolation, since I've heard about these before. But the book illustrates the how and why and puts a face behind all of the facts we learn about in class." Students also made connections to their academic experiences which prepared them to be SLP clinicians, remarking that it was the "personal" look at disability explored through the "book club" book that made it stand out from the more clinical view that was often explored in other elements of their coursework. In fact, the large majority of reflection papers $(79 \%)$ were identified with the code "applicable to clinical experiences" reflecting the idea that students made direct connections between the assignment and their experiences as new clinicians. For example, one student expressed that "Paul's [the author of An Uncomplicated Life] perspective allowed me to gain insight to a parent's viewpoint of pediatric speech-language difficulties, rather than the clinical standpoint that we, as speech-pathology students, are so often offered" while another stated, "This book gives an easy-to-read account of dealing with disability from a family's perspective, which is something that can easily get lost in translation as we learn about disabilities from the clinical perspective."

This "personal" look at disabilities also led students to recognize the limitations of some of their previous ideas regarding the extent to which disabilities impact everyday life. An idea that came up in many student reflection papers was that their previous conceptions in this area were relatively superficial. For example, one student stated that, "I was familiar with the pediatric speechlanguage disabilities mentioned in this book due to dyslexia, cerebral palsy, and deafness; however, I did not realize the extent of the disorders and the tremendous impact that they have on a student's life." Another student stated, "Having read a wide variety of textbooks, magazines, and research articles related to the field of speech language pathology, I can confidently say that this book has contributed to my knowledge of children with Down Syndrome on a much more intimate level than more concrete readings." 
The authentic accounts described in the "book club" books also helped students better understand that not everyone experiences and processes disability in the same way. Approximately half of the papers were identified with the codes "reality of disabilities over theory" and "importance of individual over diagnostic label" (53\% and 47\% respectively). As explained in Table 2, both of these codes explore the themes of authenticity and individuality reflecting the idea that not everyone experiences disabilities in the same ways. Many reflection papers noted how the diversity of experiences described in the "book club" books led them to question previously held assumptions about the most helpful way to interact with children and families impacted by disabilities. For example, one student noted that she thought poems like "Welcome to Holland" (Kingsley, 1987) would be largely viewed as helpful by parents in terms of acceptance and dealing with emotions of having a child diagnosed with a disability. However, they noted that the father in Schuyler's Monster reacted very negatively to this poem because he strongly "rejected the idea of calling for "nothing less than acceptance' in the face of a disability." On the other hand, a student was surprised and not expecting the quick resilience shown by Jillian's parents in $A n$ Uncomplicated Life saying, "In courses throughout my undergraduate and graduate career, I've learned that many families (parents in particular) undergo the 5 stages of grief after learning their child has a disability... It seemed as though Paul and Kerry did go through these 5 stages, however more briefly than I would expect." The fact that students' ideas were expanded and previous assumptions were challenged is supported by the fact that $65 \%$ of papers were coded as containing information that was "surprising" to students.

A key aspect of their experience reading these "personal" narratives is that students recognized themselves developing an emotional connection and deepened sense of empathy and understanding for the challenges children with disabilities and their families may face. Students reported strong emotions while reading these books and found themselves imagining themselves in the situation described in the books. Over half the reflection papers (59\%) were identified by the code "empathy." For example, one student said that because the book was such an "intimate account" that it "often made me wonder what I would do as a parent of a child with a possibly lifethreatening disorder or as a wife in need of a tremendous amount of support to deal with the heartaches." Another student who was a parent herself revealed, "There were so many times when I got emotional listening to this book. As a parent, you can't help but think of your own family when you hear about other children and their experiences." Students made connections between these strong emotions and their developing feelings of empathy and compassion. For example, one student explained that "while we are typically aware of the behind the scenes challenges that exist in raising a child with special needs, there is a major difference in knowing that these challenges exist and experiencing them first hand...actually hearing it from someone who experienced it can make us more empathetic and understanding." Another stated, "It is common for SLPs to get 'caught up' in assessment and treatment and forget what the client is experiencing. This book will help SLPs develop empathy and compassion for their clients." In summary, analysis of student reflection papers suggests the personal and up-close look at children and families experiencing disability was a key element of the books that led graduate students to develop feelings of empathy and compassion; both key elements of the "concern for individuals served" professional standard as described by the CAA. 
Descriptions of Interactions between Families and Professionals Provided Students with Practices to Emulate and to Avoid. Through this assignment, students gained insight into the reality of how families impacted by disability navigate specialized services and the educational system. As part of this, students identified numerous positive stories of families' experiences interacting with educational and clinical professionals which they aimed to emulate in their own practices. They also identified negative aspects of families' experiences, such as encounters with jaded professionals that inspired them to develop into caring professionals who would help families counteract or avoid similarly negative experiences. Nearly $80 \%$ of reflection papers were identified by the code "inspirational," indicating that this assignment inspired students and how they envisioned themselves as future clinicians. Codes such as, "impact of SLP on personal \& family life" and "importance of SLP's words on people's lives" (coded in 26\% and 18\% of papers respectively) highlighted certain aspects of clinical interactions students hoped to emulate or avoid as future SLPs.

Positive interactions with professionals provided practices to emulate. Students noted many positive interactions between professionals and families impacted by disabilities in the "book club" books. They noted professionals who went out of their way to go the "extra mile" with students, who built close and caring relationships with families, as well as those who were creative and unrelenting in their quest to help a child and make a difference for a family.

In terms of professionals who went the extra mile to help children, one student who read How Did You Get Here? specifically described being impressed by a story of a professional who made the decision to teach technology to a student and how this interaction made an unexpectedly large impact on the child's life. She wrote, "It was interesting to learn that a simple consideration impacted him for the rest of his life. This taught me that it is important to at least try to push your ideas as an SLP and that the worst that could happen to the idea is that it no longer gets implemented." These books also highlighted professionals that built close and caring relationships with the families. For example, many students who read An Uncomplicated Life remarked on the close relationship between Jillian and her SLP noticing that they kept in touch for years. One student was inspired by this close relationship saying, "It details the difference that individual SLPs can make in the lives of the clients." The breakthrough for Schuyler in Schuyler's Monster finally happened when she became connected with professionals who were willing to be creative and relentless in the quest to help her communicate. Related to this, one student noted, "The openminded professionals who thought outside the box were the ones that were able to connect with Schuyler and open the door for communication for her." Another student said, "Schuyler's story served as a lesson to never give up on any child's wish to communicate."

Students largely made connections between the stories of positive interactions between professionals and families described in the "book club" books and their aspirations for the kind of professional they strived to become. One student who read How Did You Get Here? remarked, "It is nice to hear these stories and feel that your professional work has the ability to have a lasting positive effect. It is easy for us to get wrapped up in the moment and lose focus on the future of our clients." Related to this same book, another student stated, "It was a great feeling to know that I could possibly work with students like the ones mentioned in the book and impact their life in this manner." Reading about parents' positive experiences, particularly interacting with SLPs, also made students more aware of the power and impact of their work which reminded them why they 
pursued this field in the first place. For example, one student wrote, "Reading this book [An Uncomplicated Life] reminded me of why I first pursued this field; Jillian's father told readers that the SLP helped her communicate, a skill that can impact all areas of life and overall quality of life." Multiple students referred specifically to how Robert described his daughter's SLP as her "her first angel" noting that "his positive experiences with Jillian's speech therapy made me motivated to be that inspiring to those that I will one day provide services to." In summary, students made direct connections between the content of the "book club" books and their inspirational feelings to develop into compassionate clinicians.

Negative interactions with professionals gave examples of practices to avoid. In their reflection papers, students also made notes of the negative interactions between the families featured in the "book club" books and the professionals meant to aid or support the family in some manner. They noted professionals who did not follow evidence-based practice, those who seemed to fail to take the time to see children as individuals, and those who had lowered expectations for students based on their disability status. All of these negative interactions were disappointing to students given what they had learned about special education policies and the progress made regarding knowledge on how to treat disabilities. Summing up this sentiment, one student, who read How Did They Get Here? noted that "decades after the passing of IDEA and section 504, it still seems, after reading this book, to be an unfair uphill battle for parents of and individuals with 'disabilities' in terms of education."

Resistance to fully including children with disabilities in general education classrooms was one of the most notable examples of failure to follow evidence-based practice that students noted in their reflection papers. For example, one student wrote about the negative experiences Jillian's family faced when advocating for her to receive an inclusive education as described in An Uncomplicated Life. The student shared, "I was surprised at the inconsistent willingness of her school to provide a fair and appropriate education," and went on to explain that, "they are parents who wanted her to be included in the least restrictive environment; I would have thought this would be more welcomed by the district rather than considered such a problem." Failure to follow best practices was also notable in Schuyler's Monster when the family encountered difficulty obtaining an appropriate AAC device. As one student stated, "The parts of the book that I found the disappointing were those in which professionals continuously let down the Rummel-Hudsons in terms of helping Schulyer gain access to AAC devices that would provide her with the most optimal opportunity to communicate."

In their reflection papers students attributed professionals' failure to follow best practice as seeming to stem from one of two possible reasons. First, they viewed some professionals as failing to take the time to get to know the children as individuals. For example, one student wrote, "Each individual child is different and no cookie-cutter solution should be applied to a child with a disability. A school should recognize that preconceived notions of children with disabilities may arise." Secondly, students noted that lowered expectations for students with disabilities was another driver behind the failure to follow best practice. For example, one student wrote, "This book also solidified the concept that a diagnosis does not define a child's abilities and that they should not be limited by a label. Schulyer's parents were told that Schulyer may not ever be able to communicate. However, Schulyer's strong motivation combined with an appropriate AAC device allowed her to defy all expectations that had been set for her." 
In reaction to these types of observations, students affirmed their commitment to be the best possible clinicians making statements like, "As a clinician, I will strive to challenge all of my clients to meet their fullest potential without lowering my expectations based on disability status." Another student discussing her reactions to An Uncomplicated Life wrote that:

The author's description of their annual clash with the school system was frustrating to read, especially as someone who may be a part of that struggle at that table at some point in the future. As a future SLP, I have only been hearing about the IEP struggle from a professional point of view. This narrative will definitely stick in my mind when developing a plan of care, as parental/familial concerns should be a priority.

In summary, analysis of the student reflection papers suggests that the experience of reading about negative interactions between professionals and families inspired graduate students to avoid these practices and, instead, demonstrate compassion and embody hope.

Interactions between Families and Professionals Inspired Advocacy. The authentic nature of the "book club" books as well as the detailed descriptions of the positive and negative interactions between families and professionals provided impetus for students to recognize the power of advocacy. This recognition inspired students to become strong advocates for children with disabilities as part of their role as an SLP. It also inspired students to consider encouraging parents to be strong advocates for their children. As mentioned before, nearly $80 \%$ of papers were coded as "inspirational." This finding is particularly important because encouraging "active involvement of the individual served in his or her own care" is a key part of the "concern for individuals served" CAA professional practice standard.

A major theme of each of the "book club" books is the impact that parental advocacy had on the lives of their children. For example, one student reflection paper on An Uncomplicated Life noted, "I was also very inspired by her parents and their consistent support and insistence in getting her the best services and opportunities in order to not limit her abilities... their dedication to providing Jillian with all of life's experiences was very inspiring." Students who read How Did You Get Here? noted, "It is apparent from the stories in this book that parents of students with disabilities play an active role in their children's lives otherwise their children will suffer and not achieve their highest potential," and "This book opened my eyes to how important familial support and selfadvocacy are for students who want more out of their education and who constantly have to make sure that they are provided with the appropriate modifications and accommodations." A student who read Schuyler's Monster wrote, "I actually found some of the most inspirational aspects of the book to center around how heavily the parents advocated for Schulyer and her right to communicate. Without their constant effort and advocacy, it is unknown whether Schulyer would have ever ended up with a way to communicate effectively with others."

As a result of reading about the importance of parental advocacy, students largely reflected that they were inspired both to be stronger advocates for children with disabilities but also to encourage and support parents to be their child's own best advocate. For example, one student reflected that, "I think all clinicians should aspire to be the SLP who fought the fight with them and showed a genuine interest in building a bond with their child that would last a lifetime." Another student stated, "This book helped me to understand how important it is to advocate for a child with a disability, and to never underestimate their abilities." Students drew explicit connects between 
advocacy and parent involvement. One student stated, "This book is something that could potentially open the minds of newer clinicians to being more adamant about including the parents and family in therapy throughout the process, rather than intermittently." Another student stated, "This narrative solidified the notion that parents know their children best and are truly their best advocates, regardless of the amount of time school professionals or medical pathologists spend evaluating, teaching, or observing a child." Given that advocating for children is a key part of providing appropriate care for children with language disorders in school settings, it is relevant to note that the codes "reinforce material covered in class" and "knowledge of school-based processes" were noted in $24 \%$ and $29 \%$ of papers respectively. In summary, the "book club" books provided an authentic context which facilitated students to explore the critical role of advocacy when working with children with disabilities; an idea also described and emphasized in class.

Students Perceived the "Book Club" Books Positively. The results of the anonymous survey related to the "book club" assignment suggests that students seemed to enjoy reading these books, especially in contrast to the traditional textbooks and research articles. The survey asked students to agree or disagree with the statements "For this class, I carefully read all assigned textbook chapters and empirical articles; I didn't skim them" and "I carefully read the "book club" book completely for this class; I didn't skim it." The difference between the answers to these two questions was striking. Students in this sample agreed with the statement that they carefully read the "book club" book $(\mathrm{M}=4.32, \mathrm{SD}=0.93)$ at a much higher rate than they reported carefully reading the textbook and empirical articles assigned for the class $(\mathrm{M}=1.97, \mathrm{SD}=1.15)$. Similarly, they were asked to compare their engagement with the "book club" book in contrast to the textbooks/ empirical articles. Notably, students reported finding the "book club" book more engaging $(M=3.87, S D=1.10)$ in contrast to their perceived engagement $(M=1.74, S D=0.91)$ with the textbook/ empirical articles. Similarly, students felt they gained a new perspective by reading the "book club" book $(\mathrm{M}=3.87, \mathrm{SD}=0.91)$ and that this reading helped them to engage with the course content on a deeper level $(\mathrm{M}=4.10, \mathrm{SD}=0.82)$. There seemed to be overall agreement that students appreciated the opportunity to select the book to read for this assignment. Most students disagreed with the statement, "I wish the professor had selected the book for us to read instead of providing a choice of books to select from for this assignment" $(\mathrm{M}=1.52, \mathrm{SD}=$ 0.84). Overall, most students agreed with the statement that, "Overall, I felt the "book club" assignment added value to this class." $(\mathrm{M}=4.13, \mathrm{SD}=0.66)$.

\section{Implications}

According to the Council on Academic Accreditation in Audiology and Speech-Language Pathology (CAA) 2017 standards for accreditation of graduate education programs in audiology and speech-language pathology, students must "show evidence of care, compassion, and appropriate empathy during interactions with each individual served, family members, caregivers and any others involved in care" (CAA, 2018, p. 21) as well as "encourage active involvement of the individual served in his or her own care" (CAA, 2018, p. 21) as part of the Professional Practice Competencies (3.1.1B; CAA 2018). This study was inspired by the question: How do we teach the "concern for others" professional practice competency standard within the graduate school classroom for speech-language pathology students in a genuine, enjoyable and impactful manner? Analysis of student reflection papers related to an assignment designed to meet this standard and the related survey demonstrate that that assignment, structured as an in-class "book club" centered 
around personal accounts of disabilities, was perceived as a meaningful and largely positive experience by students within the context of their graduate coursework. These findings suggest that it is feasible for faculty to address this professional standard within the graduate-level classroom through a structured assignment set up as an in-class "book club".

It is instructive to consider how and why this assignment appeared to positively impact student learning and add value to the classroom experience. An understandable worry when designing class assignments meant to inspire compassion and care is that the assignment will feel too trite or superficial. Students may have an intuitive sense that "concern" cannot be taught or a feeling that they are able to demonstrate "concern for individuals" without specifically being taught. After all, they are in graduate school for speech-language pathology. They may wonder how they could have gotten here, studying a human-facing profession focused on communication, without already clearly demonstrating that they are more than capable of demonstrating "concern for individuals." This rational student perspective makes it challenging to design impactful assignments in this area and yet the "book club" assignment appears to be relatively successful in this effort given the data presented in this paper. Further analysis suggests that there are several elements of the design of this assignment that accounted for its success in engaging students and creating an authentic learning opportunity.

Firstly, the main activity that the assignment focused on, namely reading a non-fiction book written for the popular press, stood out in a novel way from other activities in graduate-level studies. While students typically are compelled to read textbooks in graduate-level work, by and large research shows these types of reading assignments are not viewed favorably by students nor consistently completed by students (Clump \& Doll, 2007; McMinn, Tabor, Trihub, Taylor, \& Dominguez, 2009). The survey results included in this study (showing that students did not carefully read all assigned textbook chapters or find them engaging) are consistent with this research. However, the books included in this assignment were written for a mainstream audience and thus designed to be engaging. Analysis suggests students found this to be the case in this assignment. Anecdotally, a number of students shared with the instructor that they never have "time" to read such books given the rigor and demands of the graduate program and thus enjoyed the experience of reading a "fun" book.

Research on critical thinking and reading consistently shows that when students are engaged with reading, they are better positioned to engage in critical thinking which can lead to students gaining new insights and knowledge as well as both recognizing and questioning previously held assumptions (Bain, 2004). Further, research shows students show more engagement with reading and writing when there are explicit connections between reading and "real life" (Eodice, Geller, \& Lerner, 2017; Irvin, Meltzer, \& Dukes, 2007). The fact that each of the books included in this assignment prominently featured children and families interacting with SLPs, the career students were studying to enter, likely further explains how and why this assignment was both enjoyable and meaningful. Further, students were given a choice of which book to read which likely increased students' feelings of engagement and autonomy. Multiple theories and research have demonstrated promoting autonomy is positively associated with intrinsic motivation as well as engagement with learning (Brown, Roediger, \& McDaniel, 2014; Lang, 2016). Further, Ryan and Deci's (2000) self-determination theory emphasizes that feeling a sense of autonomy leads people to feel greater self-determination in approaching their goals and tasks, increasing intrinsic motivation. 
On a final note, this assignment was structured to enhance the social interaction in class. While no data during the "book club" meetings were collected or analyzed for this study, the instructor (also the author of this paper) observed that students appeared to be engaged, talkative, and enthusiastic during "book club" meetings and often brought up points from their "book clubs" at other points in the class (i.e., discussions/ presentations on textbook course material). This anecdotal piece of evidence provides additional support in terms of understanding the impact of this assignment. The idea that socialization is related to learning aligns with the notion explored in popular press that collective literary experiences such as "book clubs" fuel passions and enhance understanding of new ideas (Ahlin, 2016; Lloyd, 2011).

\section{Limitations of the Study and Areas for Future Research}

While these papers present promising research that it is indeed possible to design an assignment that successfully addresses the "concern for individuals served" CAA professional practice standard, there are a few notable limitations of the study. First, the data were collected at one large, suburban state university with a relatively small sample size. Secondly, the data were also collected in a course specifically about language disorders in the population of school-age children. Further, results analyzed in this study were based on self-report, either within the reflection papers or on the survey, which may not always be reliable. Although care was taken to minimize the risk that the students' responses were biased by the fact the primary author was also the instructor (i.e., ensuring all reflection papers were de-identified, administering the survey as an anonymous webbased survey, and having all analyses take place after course grades were compiled and submitted), it is still possible the author's involvement with the assignment impacted the value of the data collected. Finally, although student learning was gauged through surveys and reflection papers, there was not an exam or quiz associated with the book content specifically, so it is difficult to quantify or accurately pinpoint the learning in this class which is associated with this assignment specifically.

Given the promising results of this study, further research on the impact of this or similar assignments seems warranted. Future studies could examine the uses of this assignment across different areas or disorders addressed in the field of communication sciences and disorders. For example, a future study could investigate the impact of a similar "book club" assignment in a class on hearing loss or acquired adult language disorders. In order to more fully gauge whether the assignment was successful in preparing students to be sensitive and empathetic clinicians, it would be useful to consider collecting pre- and post-assignment data to allow a deeper exploration of the impact of this assignment on student learning. The pre-assignment data collection might take the form of a questionnaire, reflection paper, or structured interview around empathy and compassion. Further, in terms of future investigations, it would also be interesting to determine if the book selections moderated students' perceived value and learning from the assignment. While student autonomy in book selection appeared to be a key factor related to student engagement, it is possible certain books were more and less helpful in terms of facilitating student learning and this variation was not specifically investigated in this study. 


\section{Conclusion}

This research study addresses an important gap in the literature regarding teaching qualities such as empathy and compassion to graduate students in speech-language pathology. This is a worthwhile topic to explore particularly in light of the 2017 CAA accreditation standard "concern for individuals served." The assignment under investigation involved student participation in an in-class "book club" centered around reading non-fiction books detailing personal accounts of children and families impacted by disabilities in a graduate-level class focused on school age language disorders. Analysis of student reflection papers suggests the assignment provided students with an authentic and compelling look at the lives of families and children impacted by disabilities, inspired feelings of empathy and provided examples of clinical interactions to either emulate or avoid. Survey results suggest this assignment was perceived positively by students and seen as an enjoyable supplement to textbook reading.

Taken together, these findings suggest that it is both feasible as well as practical for graduate-level instructors to address this professional standard within the graduate-level classroom. Emphasizing to students the importance of compassion and concern is increasingly important in this age of high caseloads, litigious IEPs meeting, and challenging demands for productivity. Graduate education is a prime opportunity to emphasize to new clinicians that textbook knowledge alone does not make a great clinician. A clinician's ability to show care and compassion to the individuals under their care may be what differentiates a merely competent clinician from one who truly makes a difference in the life of a child or a family. This recognition is likely what inspired CAA to add the "concern for individuals served" professional practice competency to the 2017 standards. It is also the idea that inspired the design of the "book club" assignment and the associated research described in this paper. In the words of the great ethologist Jane Goodall, "It is these undeniable qualities of human love and compassion and self-sacrifice that give me hope for the future" (Goodall \& Berman, 1999, p. 148).

\section{References}

Ahlin, C. (2016, January 29). 11 reasons every woman should join a book club [Online article]. Retrieved from https://www.bustle.com/articles/138281-11-reasons-every-woman-shouldjoin-a-book-club

American Federation of Teachers. (2010). Classroom tips: Building parent-teacher partnerships. Washington, DC: American Federation of Teachers.

American Speech-Language-Hearing Association. (2018). 2018 Schools survey: Survey summary report: Numbers and types of responses, SLPs [PDF]. Retrieved from https://www.asha.org/uploadedFiles/2018-Schools-Survey-Summary-Report.pdf

Bain, K. (2004). What the best college teachers do. Cambridge, MA: Harvard University Press.

Bogdan, R., \& Biklen, S. (1998). Qualitative research for education: An introduction to theory and methods, Third Edition. London, England: Pearson.

Brown, P. C., Roediger III, H. L., \& McDaniel, M. A. (2014). Make it stick: The science of successful learning. Cambridge, MA: The Belknap Press of Harvard University Press.

Council on Academic Accreditation in Audiology and Speech-Language Pathology. (2010). ASHA documents [PDF]. Retrieved from https:/utep.edu/chs/slp/_Files/docs/3-ASHADocuments.pdf 
Council on Academic Accreditation in Audiology and Speech-Language Pathology. (2018). Standards for accreditation of graduate education programs in audiology and speechlanguage pathology (2017). Retrieved from https://caa.asha.org/wpcontent/uploads/Accreditation-Standards-Documentation-Guidance.pdf

Clump, M. A., \& Doll, J. (2007). Do the low levels of reading course material continue? An examination in a forensic psychology graduate program. Journal of Instructional Psychology, 34(4), 242-246.

Cutter, M. \& Polovoy, C. (2014). Under pressure. The ASHA Leader, 19(6), 36-44.

De Froy, A. (2018). Tough talks. The ASHA Leader, 23(4), 36-37.

Dunst, C. J., \& Dempsey, I. (2007). Family-professional partnerships and parenting competence, confidence, and enjoyment. International Journal of Disability, Development \& Education, 54(3), 305-318.

Eodice, M., Geller, A. E., \& Lerner, N. (2017). The meaningful writing project: Learning, teaching, and writing in higher education. Louisville, CO: Utah State University Press.

Felton, J. S. (1998). Burnout as a clinical entity: Its importance in health care workers. Occupational Medicine, 48(4), 237-250.

Gold, R. \& Gold, A. (2018). Delivering bad news: Attitudes, feelings, and practice characteristics among speech-language pathologists. American Journal of Speech-Language Pathology, 27(1), 108-122.

Goodall, J., \& Berman, P. (1999). Reason for hope: A spiritual journey. New York, NY: Warner Books.

Hehir, T. (1990). The impact of due process on the programmatic decisions of special education directors (Unpublished doctoral dissertation). Harvard Graduate School of Education, Cambridge, MA.

Hehir, T., Figueroa, R., Gamm, S., Katzman, L. I., Gruner, A., Karger, J., \& Hernandez, J. (2005). Comprehensive management review and evaluation of special education. (Report submitted to the New York City Department of Education). Retrieved from https://www.uft.org/files/attachments/hehir-report.pdf

Irvin, J. L., Meltzer, J., \& Dukes, M. (2007). Taking action on adolescent literacy: An implementation guide for school leaders. St. Alexandria, VA: Association for Supervision \& Curriculum Development.

Keltner, D. (2009). Born to be good: The science of a meaningful life. New York, NY: W.W. Norton \& Company, Inc.

Kingsley, E. P. (1987). Welcome to Holland [Webpage]. Retrieved from http://www.ourkids.org/Archives/Holland.html

Kreider, H., Mayer, E., \& Vaughan, P. (1999). Early childhood digest: Helping parents communicate better with schools. Cambridge, MA: Harvard Family Research Project.

Lang, J. M. (2016). Small teaching: Everyday lessons from the science of learning. San Francisco, CA: Jossey-Bass.

Lloyd, D. (2011, May 25). Five reasons to join a book club [Bog post]. Retrieved from https://www.huffingtonpost.com/delia-lloyd/five-reasons-to-join-a-bo_b_476162.html

Luterman, D. M. (2001). Counseling persons with communication disorders and their families (4th ed.). Austin, TX: Pro-Ed.

Maxwell, J. A. (2005). Qualitative research design: An interactive approach. (2nd ed.). Thousand Oaks, CA: Sage Publications, Inc.

McMinn, M. R., Tabor, A., Trihub, B. L., Taylor, L., \& Dominguez, A. W. (2009). Reading in 
graduate school: A survey of doctoral students in clinical psychology. Training and Education in Professional Psychology, 3(4), 233-239.

Noss, E. C. \& Yeager, K. R. (2016). Beyond the clinic and classroom. The ASHA Leader, 21(10), 36-37.

Park, S., Stone, S., \& Holloway, S. (2017). School-based parental involvement as a predictor of achievement and school learning environment: An elementary school-level analysis. Children and Youth Services Review, 82, 195-206.

Roberts, M. Y., Hensle, T., \& Brooks, M. K. (2016). More than "try this at home"-Including parents in early intervention. Perspectives of the ASHA Special Interest Groups, 1(1), 130143.

Ryan, R. M., \& Deci, E. L. (2000). Self-determination theory and the facilitation of intrinsic motivation, social development, and well-being. American Psychologist, 55(1), 68-78.

Seidman, I. (2006). Interviewing as qualitative research: A guide for researchers in education and social sciences (3rd ed.). New York, NY: Teachers College Press.

Story, C. M. (2017, July 10). 5 reasons why you need to belong to a book club [Blog post]. Retrieved from http://www.writingandwellness.com/2017/07/10/5-reasons-why-youneed-to-belong-to-a-book-club/

Strauss, A., \& Corbin J. (1998). Basics of qualitative research: Techniques and procedures for developing grounded theory (2nd ed.). London, England: SAGE Publications.

Sylvan, L. (2014) Speech-language services in public schools: How policy ambiguity regarding eligibility criteria impacts speech-language pathologists in a litigious and resource constrained environment. Journal of the American Academy of Special Education Professionals, Fall 2014, 7-23.

Sylvan, L. (2018). Similar populations, differing service levels: Exploring factors that drive variability in the provision of speech-language Services. Educational Policy, 32(4), 598630.

Woodman, A. C. (2014). Trajectories of stress among parents of children with disabilities: A dyadic analysis. Family Relations, 63(1), 39-54.

Yu, B. \& Epstein, L. (2011). Facilitating critical reflections about disability among students in speech-language pathology. Perspectives on Issues in Higher Education, 14(1), 11-20. 